\title{
On the Heats of Solvation of the Zinc(II), Cadmium(II) and Mercury(II) Ions, and of their Neutral Halide Complexes, in Water and Dimethyl Sulfoxide at $25^{\circ} \mathrm{C}$
}

\author{
STEN AHRLAND, LENNART KULLBERG and ROBERTO PORTANOVA*
}

Inorganic Chemistry 1, Chemical Center, University of Lund, P.O.Box 740, S-220 07 Lund, Sweden

Heats of solution have been determined for the zinc(II), cadmium(II) and mercury(II) halides in dimethyl sulfoxide (DMSO), and for the cadmium(II) halides also in water. Combined with data from the literature, the values measured yield the solvation enthalpies of the neutral complexes $\mathrm{ML}_{2}$. These are much larger for zinc(II) and cadmium(II) than for mercury(II), indicating that the solvent molecules are much more loosely bound in the latter case. Evidently, in the nearly linear complexes $\mathrm{HgL}_{2}$ no solvent molecules are really close to the metal ion which they certainly are in the complexes $\mathrm{ZnL}_{2}$ and $\mathrm{CdL}_{2}$.

From the heats of solvation, the complex formation enthalpies and the lattice enthalpies, the sums of the solvation enthalpies of the ions present in each compound $\mathrm{ML}_{2}$ can be calculated. If two reasonable extrathermodynamic assumptions are introduced, the solvation enthalpies of the ions $\mathrm{Zn}^{2+}, \mathrm{Cd}^{2+}$ and $\mathrm{Hg}^{2+}$ in both water and DMSO can also be found. In both solvents, $\mathrm{Zn}^{2+}$ is more strongly solvated than $\mathrm{Cd}^{2+}$ which, however, is somewhat less strongly solvated than $\mathrm{Hg}^{2+}$. The difference between $\mathrm{Zn}^{2+}$ and $\mathrm{Cd}^{2+}$ is larger in water than in DMSO, while the difference between $\mathrm{Cd}^{2+}$ and $\mathrm{Hg}^{2+}$ is smaller in water than in DMSO. These trends reflect the different character of the bonds formed by the various acceptors.

For the past few years the thermodynamics of metal complex formation in dimethyl sulfoxide, DMSO, have been studied in this laboratory and the results compared to those found previously for

\footnotetext{
* Present address: Istituto Impianto Nucleari, Universita di Palermo, Viale delle Scienze, I-90128 Palermo, Italy.
}

analogous reactions in aqueous solutions. Particularly the complexes formed between the divalent $d^{10}$ ions of the zinc group and the heavy halides $\mathrm{Cl}^{-}$, $\mathrm{Br}^{-}$and $\mathrm{I}^{-}$have been thoroughly investigated. These metal ions vary greatly in their bonding properties, from the distinctly hard $\mathrm{Zn}^{2+}$ via the mildly soft $\mathrm{Cd}^{2+}$ to the very soft $\mathrm{Hg}^{2+}$. Also the bonding character of the ligands spans a wide range, from the mildly soft $\mathrm{Cl}^{-}$via the softer $\mathrm{Br}^{-}$to the very soft $\mathrm{I}^{-}$. This means that in these systems complexes of widely different bonding characteristics are formed.

Both in water and DMSO the three metal ions mentioned are certainly all surrounded by six solvent molecules in a regular octahedral arrangement. ${ }^{1-4}$ Their halide complexes are formed according to different patterns, however. ${ }^{3,5-9}$ The final complex formed is without exception the tetrahedral $\mathrm{ML}_{4}^{2-}$. For mercury(II) the neutral complexes $\mathrm{HgL}_{2}$ generally have a linear structure which has no counterpart for cadmium(II) or zinc(II). The linear $\mathrm{HgL}_{2}$ complexes have long been known both in crystalline and gaseous phases. ${ }^{10}$ By recent $\mathrm{X}$-ray diffraction measurements, linear or nearly linear complexes have been proved to exist also in solutions. ${ }^{8,9}$ For cadmium(II) and zinc(II), thermodynamic data also strongly suggest that the switch is directly from octahedral to tetrahedral coordination. $^{11,12}$ They indicate, moreover, that the change of coordination generally occurs at an earlier step for $\mathrm{Zn}^{2+}$ than for $\mathrm{Cd}^{2+}$. This happens earlier in DMSO than in water. For the zinc chloride and bromide systems, the switch seems mainly to take place already at the first step in DMSO but at the second step in water. On account 
of the weak complex formation, no definite conclusions can be drawn for the zinc iodide system in water. In DMSO, however, it seems that the change occurs mainly at the second step. For the cadmium halide systems, the change of coordination takes place at the second step in DMSO but at the third step in water.

Complex formation equilibria in solution depend very much upon the solvation of the various species involved. This is why a knowledge of such parameters as the free energy, enthalpy and entropy of solvation is likely to shed light on the thermodynamic parameters of the complex formation reactions.

The free energy and heat of solvation should increase with the number of solvent molecules entering into close contact with the acceptor. Other factors will of course also influence the solvation parameters. The charge and size of acceptor and ligand, their capacities for covalent bonding, and the donor properties of the solvent all intricately contribute to the final outcome.

The heat of solvation of neutral complexes can be determined without any extrathermodynamic assumptions, by combining the heat of sublimation and the heat of solution which can both be experimentally determined. In this investigation, the heats of solvation of the neutral chloride, bromide, and iodide complexes of the zinc group metals in water and DMSO have been determined. Heats of sublimation have been obtained from literature data and heats of solution have been measured calorimetrically.

From the results obtained, heats of solvation of the free ions have also been derived. The heat of solvation of individual ions cannot be found without an extrathermodynamic assumption. Any evaluation from experimental data always gives the sum of the heats of solvation of the positive and negative ions of the electrolyte involved. In the present study, the quantities primarily obtained are therefore the sum of the heats of solvation of $\mathrm{M}^{2+}\left(=\mathrm{Zn}^{2+}, \mathrm{Cd}^{2+}\right.$ or $\left.\mathrm{Hg}^{2+}\right)$ and $2 \mathrm{~L}^{-}\left(=\mathrm{Cl}^{-}, \mathrm{Br}^{-}\right.$or $\left.\mathrm{I}^{-}\right)$. These are found by combining the heats of reaction measured, the lattice enthalpies found by means of a BornHaber cycle and the enthalpy changes for the complex formation reactions which have been obtained previously. By means of extrathermodynamic assumptions that we consider reasonable, the individual heats of solvation for the halide ions have been calculated both in water and in DMSO. From these, we have been able to calculate the heats of solvation of $\mathrm{Zn}^{2+}, \mathrm{Cd}^{2+}$ and $\mathrm{Hg}^{2+}$ in both solvents.

\section{CALCULATIONS AND NOTATIONS}

The heat of solvation of the neutral complex $\mathrm{ML}_{2}$, $\Delta H_{\mathrm{sv}}^{\circ}\left(\mathrm{ML}_{2}\right)$, pertaining to the reaction

$\mathrm{ML}_{2}(\mathrm{~g}) \rightarrow \mathrm{ML}_{2}$ (solv)

is obtained from the heat of sublimation, $\Delta H_{\text {sub }}^{\circ}\left(\mathrm{ML}_{2}\right)$, pertaining to

$\mathrm{ML}_{2}(\mathrm{~s}) \rightarrow \mathrm{ML}_{2}(\mathrm{~g})$

and the heat of solution, $\Delta H_{\mathrm{s}}^{\circ}\left(\mathrm{ML}_{2}\right)$, pertaining to

$\mathrm{ML}_{2}(\mathrm{~s}) \rightarrow \mathrm{ML}_{2}$ (solv)

through the relation

$\Delta H_{\mathrm{sv}}^{\circ}\left(\mathrm{ML}_{2}\right)=\Delta H_{\mathrm{s}}^{\circ}\left(\mathrm{ML}_{2}\right)-\Delta H_{\mathrm{sub}}^{\circ}\left(\mathrm{ML}_{2}\right)$

If the complex $\mathrm{ML}_{2}$ is not very stable in solution, a more or less extensive dissociation will take place when the salt is dissolved. In many systems reactions involving a disproportionation of the complex also occur. The heats actually measured have to be corrected for effects due to such reactions, in order to provide the quantity $\Delta H_{s}^{\circ}\left(\mathrm{ML}_{2}\right)$. This requires not only that the compositions of the equilibrium solutions can be calculated from the pertinent stability constants, but also that the enthalpy changes of all the dissociation and disproportionation reactions involved are known. As regards the present systems, extensive dissociation and/or disproportionation takes place for the zinc and cadmium halides, while the mercury ones remain virtually unchanged. The stability constants and enthalpy changes necessary for the calculation of $\Delta H_{s}^{\circ}\left(\mathrm{ML}_{2}\right)$ for the zinc and cadmium complexes have all been measured, ${ }^{11-13}$ though the values determined for the very weak zinc complexes formed in aqueous solution are not sufficiently precise for the present purpose. ${ }^{13}$ These measurements all refer to a temperature of $25{ }^{\circ} \mathrm{C}$ and to ionic media of $1 \mathrm{M} \mathrm{NaClO}_{4}$ in water and $1 \mathrm{M} \mathrm{NH}_{4} \mathrm{ClO}_{4}$ in DMSO. Consequently, the same conditions have been chosen for the present study.

For the ion solvation reaction

$\mathrm{M}^{2+}(\mathrm{g})+2 \mathrm{~L}^{-}(\mathrm{g}) \rightarrow \mathrm{M}^{2+}($ solv $)+2 \mathrm{~L}^{-}$(solv)

Acta Chem. Scand. A 32 (1978) No. 3 
the enthalpy change is

$\Delta H_{\mathrm{sv}}^{\circ}(\mathrm{M}, 2 \mathrm{~L})=\Delta H_{\mathrm{sv}}^{\circ}(\mathrm{M})+2 \Delta H_{\mathrm{sv}}^{\circ}(\mathrm{L})$

where $\Delta H_{\mathrm{sv}}^{\circ}(\mathrm{M})$ and $\Delta H_{\mathrm{sv}}^{\circ}(\mathrm{L})$ are the heats of solvation of $\mathrm{M}^{2+}$ and $\mathrm{L}^{-}$, respectively. The quantity $\Delta H_{\mathrm{sv}}^{\circ}(\mathrm{M}, 2 \mathrm{~L})$ is related to the enthalpy change $\Delta H_{s}^{\circ}(\mathrm{M}, 2 \mathrm{~L})$ of the solution reaction

$\mathrm{ML}_{2}(\mathrm{~s}) \rightarrow \mathrm{M}^{2+}($ solv $)+2 \mathrm{~L}^{-}$(solv)

according to

$\Delta H_{\mathrm{sv}}^{\circ}(\mathrm{M}, 2 \mathrm{~L})=\Delta H_{\mathrm{s}}^{\circ}(\mathrm{M}, 2 \mathrm{~L})+\Delta H_{\mathrm{lat}}^{\circ}$

where $\Delta H_{\text {lat }}^{\circ}$ is the lattice enthalpy of the salt $\mathrm{ML}_{2}$, i.e. the enthalpy change of the reaction

$\mathrm{M}^{2+}(\mathrm{g})+2 \mathrm{~L}^{-}(\mathrm{g}) \rightarrow \mathrm{ML}_{2}(\mathrm{~s})$

The heats of solution pertaining to the ions and to the neutral complex are related according to

$\Delta H_{\mathrm{s}}^{\circ}(\mathrm{M}, 2 \mathrm{~L})=\Delta H_{\mathrm{s}}^{\circ}\left(\mathrm{ML}_{2}\right)-\Delta H_{\beta 2}^{\circ}$

where $\Delta H_{\beta 2}^{\circ}$ is the enthalpy change of the reaction

$\mathrm{M}^{2+}($ solv $)+2 \mathrm{~L}^{-}$(solv) $\rightarrow \mathrm{ML}_{2}$ (solv)

For the calculation of $\Delta H_{\mathrm{sv}}^{\circ}(\mathrm{M}, 2 \mathrm{~L})$, the values of
$\Delta H_{\beta 2}^{\circ}$ have thus to be known not only for the zinc and cadmium, but also for the mercury(II) systems.

\section{EXPERIMENTAL}

Materials. The salts used were all of analytical grade. Dry zinc chloride and bromide were prepared by heating the pure "anhydrous" salts in a stream of dry hydrogen chloride and bromide gas, respectively. Traces of these gases were afterwards removed by a stream of dry nitrogen. The zinc iodide was recrystallized from water and then dried by heating in a dry nitrogen atmosphere. The dry salts are extremely hygroscopic and have to be very carefully protected from moisture.

The cadmium halides were dehydrated by heating to $80{ }^{\circ} \mathrm{C}$ overnight.

The mercury(II) chloride, bromide, and iodide (red) were recrystallized from hot water, alcohol, and acetone, respectively, and dried over silica gel.

The sodium and ammonium perchlorates and the DMSO were purified and analyzed as described before. $^{14-15}$

The calorimetric apparatus and procedure have been described previously. ${ }^{16}$ Varying amounts of the salts $(0.05-0.5 \mathrm{~g})$ were transferred into ampoules in a dry-box. The ampoules were sealed in the box and then weighed. The salts were dissolved in 80.0 $\mathrm{ml}$ of solution which in no case took more than $10 \mathrm{~min}$. At least six separate experiments were performed for each salt and solvent. All the measurements were performed at $25^{\circ} \mathrm{C}$.

Table 1. Solvation enthalpies for neutral complexes, $\mathrm{ML}_{2}$, in water and DMSO, i.e. $\Delta H_{\mathrm{sv}}^{\circ}\left(\mathrm{ML}_{2}\right)$ for the reactions $\mathrm{ML}_{2}(\mathrm{~g}) \rightarrow \mathrm{ML}_{2}(\mathrm{solv})$, calculated from the dissolution and sublimation enthalpies of the solid compounds according to eqn. (1). Values in $\mathrm{kJ} \mathrm{mol}^{-1} ; 25^{\circ} \mathrm{C}$.

\begin{tabular}{|c|c|c|c|c|c|}
\hline \multirow{2}{*}{$\mathrm{ML}_{2}$} & \multirow{2}{*}{$\Delta H_{\text {sub }}^{\circ}$} & \multicolumn{2}{|l|}{ Water } & \multicolumn{2}{|c|}{ DMSO } \\
\hline & & $\Delta H_{\mathrm{s}}^{\circ}$ & $\Delta H_{\mathrm{sv}}^{\circ}$ & $\Delta H_{\mathrm{s}}^{\circ}$ & $\Delta H_{\mathrm{sv}}^{\circ}$ \\
\hline $\begin{array}{l}\mathrm{ZnCl}_{2} \\
\mathrm{ZnBr}_{2} \\
\mathrm{ZnI}_{2}\end{array}$ & $\begin{array}{l}149.0^{a} \\
145.0^{a} \\
140.4^{a}\end{array}$ & & & $\begin{array}{l}-70.0 \\
-75.9 \\
-84.1\end{array}$ & $\begin{array}{l}-219 \\
-221 \\
-224.5\end{array}$ \\
\hline $\begin{array}{l}\mathrm{CdCl}_{2} \\
\mathrm{CdBr}_{2} \\
\mathrm{CdI}_{2}\end{array}$ & $\begin{array}{l}180^{b} \\
163^{b} \\
146^{b}\end{array}$ & $\begin{array}{r}-13.7 \\
-7.3 \\
4.9\end{array}$ & $\begin{array}{l}-194 \\
-170 \\
-141\end{array}$ & $\begin{array}{l}-41.2 \\
-46.2 \\
-45.2\end{array}$ & $\begin{array}{l}-221 \\
-209 \\
-191\end{array}$ \\
\hline $\begin{array}{l}\mathrm{HgCl}_{2} \\
\mathrm{HgBr}_{2} \\
\mathrm{HgI}_{2}\end{array}$ & $\begin{array}{l}83.1^{c} \\
83.7^{b} \\
91.2^{b}\end{array}$ & $\begin{array}{l}14.0^{d} \\
20^{e} \\
28.9^{f}\end{array}$ & $\begin{array}{l}-69 \\
-64 \\
-62\end{array}$ & $\begin{array}{r}-21.2 \\
-17.0 \\
-4.3\end{array}$ & $\begin{array}{c}-104 \\
-101 \\
-95.5\end{array}$ \\
\hline
\end{tabular}

${ }^{a}$ From Ref. 20. ${ }^{b}$ From Ref. 21. ' From Ref. 22. ${ }^{d}$ From Ref. 19 ; in $1 \mathrm{M} \mathrm{HClO}_{4}{ }^{e}$ From Ref. 18; at variable ionic strength. ${ }^{f}$ From Ref. 17 ; in $0.5 \mathrm{M}(\mathrm{Na}, \mathrm{H}) \mathrm{ClO}_{4}$.

Acta Chem. Scand. A 32 (1978) No. 3 


\section{MEASUREMENTS AND RESULTS}

Heats of solvation of neutral complexes. In the present investigation, heats of solution have been measured for all the halides in DMSO, and for the cadmium halides also in water. The values of $\Delta H_{\mathrm{s}}^{\circ}\left(\mathrm{ML}_{2}\right)$ found are collected in Table 1 . These values are fairly precise with random errors estimated to $0.5-0.8 \mathrm{~kJ} \mathrm{~mol}^{-1}$ in DMSO and even less, $<0.2 \mathrm{~kJ} \mathrm{~mol}^{-1}$, in water. The degree of dissociation and disproportionation of a salt depends on its concentration. We found the same value of $\Delta H_{\mathrm{s}}^{\circ}\left(\mathrm{ML}_{2}\right)$ independent of the amount of salt dissolved so the corrections introduced to account for these reactions are evidently correct.

The mercury(II) bromide is very sparingly soluble in water and the iodide even less. A determination of $\Delta H_{\mathrm{s}}^{\circ}\left(\mathrm{ML}_{2}\right)$ by means of the present calorimetric method is therefore not feasible for these systems. For $\mathrm{HgI}_{2}$, a value has nevertheless been determined calorimetrically, from measurements including the precipitation reaction. ${ }^{17}$ For $\mathrm{HgBr}_{2}$, on the other hand, one has to be content with a value calculated from the temperature coefficient of the solubility. ${ }^{18}$ The value given for $\mathrm{HgCl}_{2}$ has been determined calorimetrically, by much the same method as used in the present work. ${ }^{19}$ The errors of the chloride and iodide values given in Table 1 are estimated to $\pm 1 \mathrm{~kJ} \mathrm{~mol}^{-1}$, while the precision of the bromide value is probably only $\pm 4 \mathrm{~kJ} \mathrm{~mol}^{-1}$.

The heats of sublimation listed in Table 1 are claimed to be correct within 2 or $3 \mathrm{~kJ} \mathrm{~mol}^{-1}$. In all but the $\mathrm{HgBr}_{2}$ case, these errors thus contribute most to the errors of $\Delta H_{\mathrm{sv}}^{\circ}$.

Heats of solvation of individual ions. The total heats of solution, $\Delta H_{\mathrm{s}}^{\circ}(\mathrm{M}, 2 \mathrm{~L})$, of the halide salts, calculated from eqn. (4) by using the values of $\Delta H_{\mathrm{s}}^{\circ}\left(\mathrm{ML}_{2}\right)$ in Table 1, are given in Table 2, where the values of $\Delta H_{\beta 2}^{\circ}$ are also stated. The values of $\Delta H_{\mathrm{s}}^{\circ}(\mathrm{M}, 2 \mathrm{~L})$ for the zinc halide systems in water have been obtained directly from calorimetric determinations of the heats evolved when the salts are dissolved. ${ }^{25}$

The lattice enthalpies, $\Delta H_{\text {lat }}^{\circ}$, at $25^{\circ} \mathrm{C}$, wanted for the calculation of $\Delta H_{\mathrm{sv}}^{\circ}(\mathrm{M}, 2 \mathrm{~L})$ have been obtained by the Born-Haber cycle given in Fig. 1. The data used in these calculations are listed in Table 3. The heat of solvation values, $\Delta H_{\mathrm{sv}}^{\circ}(\mathrm{M}, 2 \mathrm{~L})$, obtained from eqn. (3) are given in Table 4.

From the difference $\Delta H_{\mathrm{sv}}^{\circ}(\mathrm{M}, 2 \mathrm{~L})-\Delta H_{\mathrm{sv}}^{\circ}\left(\mathrm{M}, 2 \mathrm{~L}^{\prime}\right)$, the difference in the heat of solvation between the two halide ions can be obtained. Values of $\Delta H_{\mathrm{sv}}^{\circ}(\mathrm{Cl}-\mathrm{L})$ have been calculated between the chloride ion and the bromide and iodide ions. For each of the two solvents, the three metal ions ought to give the same differences which they do, within the experimental errors, as is demonstrated by the values listed in Table 4. In Fig. 2, the differences are plotted $v s$. the ionic radii of the halide ions. In both solvents, $-\Delta H_{\mathrm{sv}}^{\circ}\left(\mathrm{L}^{-}\right)$decreases in the sequence $\mathrm{Cl}^{-}>\mathrm{Br}^{-}>\mathrm{I}^{-}$, i.e. with increasing radius of the halide ion. The decrease is much slower in DMSO than in water, however. From studies involving only alkali halides, Halliwell and Nyburg ${ }^{31}$ found

Table 2. Heats of solution, $\Delta H_{\mathrm{s}}^{\circ}(\mathrm{M}, 2 \mathrm{~L})$, in water and DMSO. The values calculated from $\Delta H_{\mathrm{s}}^{\circ}\left(\mathrm{ML}_{2}\right)$, see Table 1, and $\Delta H_{\beta 2}^{\circ}$ according to eqn. (4). All values in $\mathrm{kJ} \mathrm{mol}^{-1}$.

\begin{tabular}{|c|c|c|c|c|}
\hline \multirow{2}{*}{$\mathrm{ML}_{2}$} & \multicolumn{2}{|l|}{ Water } & \multicolumn{2}{|l|}{ DMSO } \\
\hline & $\Delta H_{\beta 2}^{\circ}$ & $\Delta H_{\mathrm{s}}^{\circ}(\mathrm{M}, 2 \mathrm{~L})$ & $\Delta H_{\beta 2}^{\circ}$ & $\Delta H_{\mathrm{s}}^{\circ}(\mathrm{M}, 2 \mathrm{~L})$ \\
\hline $\begin{array}{l}\mathrm{ZnCl}_{2} \\
\mathrm{ZnBr}_{2} \\
\mathrm{ZnI}_{2}\end{array}$ & & $\begin{array}{l}-67.2^{d} \\
-59.4^{d} \\
-51.0^{d}\end{array}$ & $\begin{array}{l}23.1^{e} \\
36.9^{e} \\
48.4^{e}\end{array}$ & $\begin{array}{r}-93.1 \\
-112.8 \\
-132.5\end{array}$ \\
\hline $\begin{array}{l}\mathrm{CdCl}_{2} \\
\mathrm{CdBr}_{2} \\
\mathrm{CdI}_{2}\end{array}$ & $\begin{array}{r}2.6^{a} \\
-6.5^{b} \\
-12.3^{a}\end{array}$ & $\begin{array}{r}-16.3 \\
-0.8 \\
17.2\end{array}$ & $\begin{array}{r}8.7^{f} \\
13.1^{f} \\
29.4^{f}\end{array}$ & $\begin{array}{l}-49.9 \\
-59.3 \\
-74.6\end{array}$ \\
\hline $\begin{array}{l}\mathrm{HgCl}_{2} \\
\mathrm{HgBr}_{2} \\
\mathrm{HgI}_{2}\end{array}$ & $\begin{array}{r}-53.6^{c} \\
-87.0^{c} \\
-143.1^{c}\end{array}$ & $\begin{array}{r}68 \\
107 \\
172\end{array}$ & $\begin{array}{l}-49.3^{g} \\
-57.5^{g} \\
-73.1^{g}\end{array}$ & $\begin{array}{l}28.1 \\
40.5 \\
68.8\end{array}$ \\
\hline
\end{tabular}

${ }^{a}$ From Ref. $23 .{ }^{b}$ From Ref. 24 ; in $3 \mathrm{M} \mathrm{NaClO}_{4} \cdot{ }^{c}$ From Ref. 17 ; in $0.5 \mathrm{M}\left(\mathrm{NaClO}_{4}, \mathrm{HClO}_{4}\right) .{ }^{d}$ From Ref. 25 ; in $2 \mathrm{M}$ $\mathrm{HNO}_{3}\left(\mathrm{ZnCl}_{2}\right.$ and $\left.\mathrm{ZnBr}_{2}\right)$ and in $2 \mathrm{M} \mathrm{HClO}_{4}\left(\mathrm{ZnBr}_{2}\right)$. ${ }^{e}$ From Ref. 12. ${ }^{\prime}$ From Ref. 11. ${ }^{g}$ From Ref. 26. 


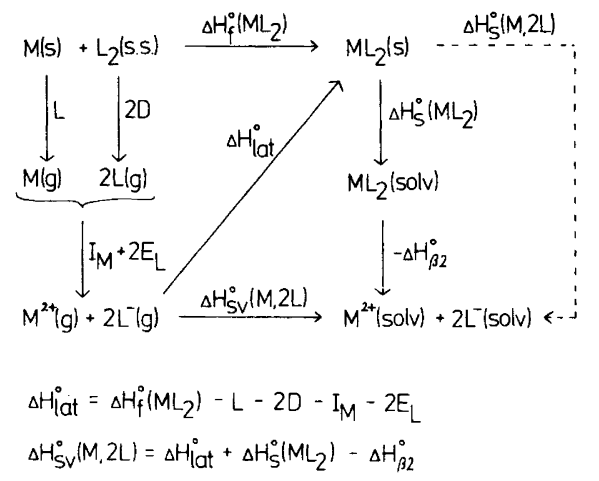

Fig. 1. The Born-Haber cycle used for the calculation of $\Delta H_{\text {lat }}^{\circ}$ and $\Delta H_{\mathrm{sv}}^{\circ}(\mathrm{M}, 2 \mathrm{~L})$.

differences $-\Delta H_{\mathrm{sv}}^{\circ}(\mathrm{Cl}-\mathrm{Br})=27 \mathrm{~kJ} \mathrm{~mol}^{-1}$ and $-\Delta H_{\mathrm{sv}}^{\circ}(\mathrm{Cl}-\mathrm{I})=68 \mathrm{~kJ} \mathrm{~mol}^{-1}$ while Morris ${ }^{32}$ found 31 and $72 \mathrm{~kJ} \mathrm{~mol}^{-1}$, respectively. Especially the latter values agree nicely with ours; $c f$. Fig. 2 and Table 4.

There is, as has been pointed out above, no purely thermodynamic way to separate $\Delta H_{\mathrm{sv}}^{\circ}(\mathrm{M}, 2 \mathrm{~L})$ into its constituent parts $\Delta H_{\mathrm{sv}}^{\circ}\left(\mathrm{M}^{2+}\right)$ and $2 \Delta H_{\mathrm{sv}}^{\circ}(\mathrm{L}), c f$. eqn. (2). Large efforts have been made to effect a reasonable partition by means of various extrathermodynamic assumptions. Aqueous solutions have naturally attracted the largest interest. The focal point of this discussion has been how to calculate

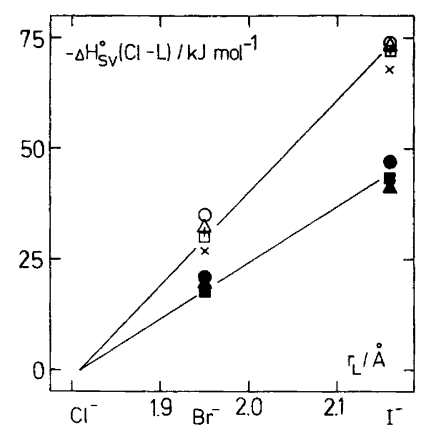

Fig. 2. Differences $\Delta H_{\mathrm{sv}}^{\circ}(\mathrm{Cl}-\mathrm{L})$ between halide ions in water and DMSO plotted vs. the ionic radii. Circles, squares and triangles refer to values obtained from $\mathrm{ZnL}_{2}, \mathrm{CdL}_{2}$ and $\mathrm{HgL}_{2}$, respectively; open signs refer to water, filled signs to DMSO. The signs $\times$ and + refer to the values found for water by Halliwell and Nyburg ${ }^{31}$ and by Morris, ${ }^{32}$ respectively.

the "best" value of the solvation enthalpy of the proton, $\Delta H_{\mathrm{aq}}^{\circ}\left(\mathrm{H}^{+}\right)$. The most satisfactory approach seems to be the semi-empirical one used by Halliwell and Nyburg. ${ }^{31}$ By this method Morris ${ }^{32}$ found $-\Delta H_{\mathrm{aq}}^{\circ}\left(\mathrm{H}^{+}\right)=1103 \pm 12 \mathrm{~kJ} \mathrm{~mol}^{-1}$. With this value as reference Morris determined, i.a., the heats of hydration of the halide ions, Table 4 , note $a$. These values have been used in the calculation of heats

Table 3. Calculation of lattice enthalpies, $\Delta H_{\text {lat }}^{\circ}$, for the reactions $\mathrm{M}^{2+}(\mathrm{g})+2 \mathrm{~L}^{-}(\mathrm{g}) \rightarrow \mathrm{ML}_{2}(\mathrm{~s})$, from the Born-Haber cycle, Fig. 1. All values in $\mathrm{kJ} \mathrm{mol}^{-1}$.

\begin{tabular}{lllllll}
\hline $\mathrm{ML}_{2}$ & $\Delta H_{\mathrm{f}}^{\circ}{ }^{a}$ & $D^{b}$ & $E^{c}$ & $L^{d}$ & $I^{e}$ & $-\Delta H_{\text {lat }}^{\circ}$ \\
\hline $\mathrm{ZnCl}_{2}$ & -416.7 & 121.8 & -348.5 & 130.5 & 2638.0 & 2731.8 \\
$\mathrm{ZnBr}_{2}$ & -328.0 & 111.7 & -324.7 & 130.5 & 2638.0 & 2670.5 \\
$\mathrm{ZnI}_{2}$ & -208.4 & 106.7 & -295.4 & 130.5 & 2638.0 & 2599.5 \\
$\mathrm{CdCl}_{2}$ & -389.1 & 121.8 & -348.5 & 111.9 & 2497.8 & 2545.4 \\
$\mathrm{CdBr}_{2}$ & -317.1 & 111.7 & -324.7 & 111.9 & 2497.8 & 2500.8 \\
$\mathrm{CdI}_{2}$ & -202.5 & 106.7 & -295.4 & 111.9 & 2497.8 & 2434.8 \\
$\mathrm{HgCl}_{2}$ & -223.4 & 121.8 & -348.5 & 61.3 & 2815.0 & 2646.3 \\
$\mathrm{HgBr}_{2}$ & -170.3 & 111.7 & -324.7 & 61.3 & 2815.0 & 2620.6 \\
$\mathrm{HgI}_{2}$ & -105.9 & 106.7 & -295.4 & 61.3 & 2815.0 & 2604.8 \\
\hline
\end{tabular}

${ }^{a}$ Standard heats of formation of the crystalline halides, i.e. $\Delta H_{\mathrm{f}}^{\circ}$ for the reactions $\mathrm{M}(\mathrm{s})+\frac{1}{2} \mathrm{~L}_{2}(\mathrm{~s}, \mathrm{~s}) \rightarrow \mathrm{ML}_{2}(\mathrm{~s})$. The values (at $298 \mathrm{~K}$ ) from Ref. 27. ${ }^{b}$ Heats of atomization of the halogens, i.e. $D$ for the reactions $\frac{1}{2} \mathrm{~L}_{2}(\mathrm{~s}, \mathrm{~s}) \rightarrow \mathrm{L}(\mathrm{g})$. The values (at $298 \mathrm{~K}$ ) from Ref. 28. ${ }^{c}$ Electron affinities of the halogen atoms, i.e. $E$ for the reactions $\mathrm{e}^{-}+\mathrm{L}(\mathrm{g}) \rightarrow \mathrm{L}^{-}(\mathrm{g})$. The values $($ at $0 \mathrm{~K})$ from Ref. $29 .{ }^{d}$ Heats of sublimation of the metals, i.e. $L$ for the reactions $\mathrm{M}(\mathrm{s}) \rightarrow \mathrm{M}(\mathrm{g})$. The values (at $298 \mathrm{~K}$ ) from Ref. 27 . $^{e}$ Ionization potentials of the metal atoms, i.e. I for the reactions $\mathbf{M}(\mathrm{g}) \rightarrow \mathrm{M}^{2+}(\mathrm{g})+2 \mathrm{e}^{-}$. The values (at $0 \mathrm{~K}$ ) from Ref. 30. 
Table 4. Solvation enthalpies of pairs of ions and determination of single-ion heats of solvation. All values in $\mathrm{kJ} \mathrm{mol}^{-1}$.

\begin{tabular}{|c|c|c|c|c|c|c|}
\hline \multirow{2}{*}{$\mathrm{M}^{2+}+2 \mathrm{~L}^{-}$} & \multicolumn{3}{|l|}{ Water } & \multicolumn{3}{|l|}{ DMSO } \\
\hline & $-\Delta H_{\mathrm{sv}}^{\circ}(\mathrm{M}, 2 \mathrm{~L})$ & $-\Delta H_{\mathrm{sv}}^{\circ}(\mathrm{Cl}-\mathrm{L})$ & $-\Delta H_{\mathrm{sv}}^{\circ}\left(\mathrm{M}^{2+}\right)^{a}$ & $-\Delta H_{\mathrm{sv}}^{\circ}(\mathrm{M}, 2 \mathrm{~L})$ & $-\Delta H_{\mathrm{sv}}^{\circ}(\mathrm{Cl}-\mathrm{L})$ & $-\Delta H_{\mathrm{sv}}^{\circ}\left(\mathrm{M}^{2+}\right)^{b}$ \\
\hline $\begin{array}{l}\mathrm{Zn}^{2+}+2 \mathrm{Cl}^{-} \\
\mathrm{Zn}^{2+}+2 \mathrm{Br}^{-} \\
\mathrm{Zn}^{2+}+2 \mathrm{I}^{-}\end{array}$ & $\begin{array}{l}2799 \\
2730 \\
2651\end{array}$ & $\begin{array}{r}0 \\
35 \\
74\end{array}$ & $\begin{array}{r}2067 \\
2060 \\
2063 \\
\end{array}$ & $\begin{array}{l}2825 \\
2783 \\
2732\end{array}$ & $\begin{array}{r}0 \\
21 \\
47\end{array}$ & $\begin{array}{r}2131 \\
2121 \\
2118 \\
\end{array}$ \\
\hline & & & Av. 2063 & & & Av. 2123 \\
\hline $\begin{array}{l}\mathrm{Cd}^{2+}+2 \mathrm{Cl}^{-} \\
\mathrm{Cd}^{2+}+2 \mathrm{Br}^{-} \\
\mathrm{Cd}^{2+}+2 \mathrm{I}^{-}\end{array}$ & $\begin{array}{l}2562 \\
2502 \\
2418\end{array}$ & $\begin{array}{r}0 \\
30 \\
72\end{array}$ & $\begin{array}{r}1830 \\
1832 \\
1830 \\
\text { Av. } 1831\end{array}$ & $\begin{array}{l}2595 \\
2560 \\
2509\end{array}$ & $\begin{array}{r}0 \\
18 \\
43\end{array}$ & $\begin{array}{r}1901 \\
1898 \\
1895 \\
\text { Av. } 1898\end{array}$ \\
\hline $\begin{array}{l}\mathrm{Hg}^{2+}+2 \mathrm{Cl}^{-} \\
\mathrm{Hg}^{2+}+2 \mathrm{Br}^{-} \\
\mathrm{Hg}^{2+}+2 \mathrm{I}^{-}\end{array}$ & $\begin{array}{l}2578 \\
2514 \\
2433\end{array}$ & $\begin{array}{r}0 \\
32 \\
73\end{array}$ & $\begin{array}{r}1846 \\
1844 \\
1845 \\
\text { Av. } 1845\end{array}$ & $\begin{array}{l}2618 \\
2580 \\
2536\end{array}$ & $\begin{array}{r}0 \\
19 \\
41\end{array}$ & $\begin{array}{r}1923 \\
1917 \\
1922 \\
\text { Av. } 1921\end{array}$ \\
\hline
\end{tabular}

${ }^{a}$ Calculated from heat of hydration values of the halide ions given in Ref. 32: $-\Delta H_{\mathrm{a} 4}^{\circ}=366,335$ and $294 \mathrm{~kJ}$ mol 1 for $\mathrm{Cl}^{-}, \mathrm{Br}^{-}$and $\mathrm{I}^{-}$, respectively. ${ }^{b}$ From heats of hydration given in Ref. 32 and heats of transfer given in Ref. 37 ; the heats of solvation of the halide ions in DMSO have been calculated to be $-\Delta H_{\mathrm{si}}^{\circ}=347,331$ and $307 \mathrm{~kJ}^{\mathrm{mol}}{ }^{-1}$ for $\mathrm{Cl}^{-}, \mathrm{Br}^{-}$and $\mathrm{I}^{-}$, respectively.

of hydration of $\mathrm{Zn}^{2+}, \mathrm{Cd}^{2+}$, and $\mathrm{Hg}^{2+}$, Table 4 . For each metal ion the three halides should give the same value of $\Delta H_{\mathrm{aq}}^{\circ}\left(\mathrm{M}^{2+}\right)$. Indeed the values found agree within a few $\mathrm{kJ} \mathrm{mol}^{-1}$, Table 4. The values of $\Delta H_{\mathrm{aq}}^{\circ}\left(\mathrm{M}^{2+}\right)$ also agree well with those given by Noyes ${ }^{33}$ in a compilation of ion hydration data. Recalculating Noyes' values to the same reference point as ours, i.e. $-\Delta H_{\mathrm{aq}}^{\circ}\left(\mathrm{H}^{+}\right)=1103$ $\mathrm{kJ} \mathrm{mol}^{-1}$, gives $-\Delta H_{\mathrm{aq}}^{\circ}=2071,1833$, and 1848 $\mathrm{kJ} \mathrm{mol}{ }^{-1}$ for $\mathrm{Zn}^{2+}, \mathrm{Cd}^{2+}$, and $\mathrm{Hg}^{2+}$, respectively. Values of $\Delta H_{\mathrm{aq}}^{\circ}\left(\mathrm{M}^{2+}\right)$ for these ions have also been reported by Ladd and Lee. ${ }^{34}$ Their values for $\mathrm{Zn}^{2+}$ and $\mathrm{Cd}^{2+}$, viz. 2067 and $1837 \mathrm{~kJ} \mathrm{~mol}^{-1}$ are close to ours, while the value quoted for $\mathrm{Hg}^{2+}$ is considerably more exothermic. Ladd and Lee calculated their $\Delta H_{\mathrm{aq}}^{\circ}\left(\mathrm{Hg}^{2+}\right)$ value from measurements on $\mathrm{HgCl}_{2}, \mathrm{HgBr}_{2}$, and $\mathrm{Hg}(\mathrm{CN})_{2}$. By means of eqn. (3) above, they found from these measurements $-\Delta H_{\mathrm{aq}}^{\circ}\left(\mathrm{Hg}^{2+}\right)=1908,1942$, and $2042 \mathrm{~kJ} \mathrm{~mol}^{-1}$, respectively. In their evaluation Ladd and Lee apparently assumed that these mercury(II) salts are all completely dissociated in aqueous solution. In fact, they dissociate very little even at low concentrations. Ladd and Lee's values can be corrected by subtracting the enthalpy changes, $\Delta H_{\beta 2}^{\circ}$, from the calculated hydration enthalpies; $c f$. eqn. (4). Christensen et al. ${ }^{17,35}$ have determined the enthalpy changes for the complex formation in the mercury(II) halide and cyanide systems. Using their $\Delta H_{\beta 2}^{\circ}$-values we find the corrected values $-\Delta H_{\mathrm{aq}}^{\circ}\left(\mathrm{Hg}^{2+}\right)=1854$, 1853 , and $1840 \mathrm{~kJ} \mathrm{~mol}^{-1}$ from the $\mathrm{HgCl}_{2}, \mathrm{HgBr}_{2}$ and $\mathrm{Hg}(\mathrm{CN})_{2}$ data, respectively. These values agree satisfactorily among themselves and the mean, 1849 $\mathrm{kJ} \mathrm{mol}^{-1}$, is indeed very close both to our value and to the modified Noyes value quoted above.

The solvation enthalpies of ions differ relatively little between different solvents. The differences are defined as enthalpies of transfer, $\Delta H_{\mathrm{tr}}^{\circ}$. Values of $\Delta H_{\mathrm{tr}}^{\circ}$ for salts are readily determined as differences between the values of $\Delta H_{\mathrm{s}}^{\circ}$ in the solvents concerned. Just as for $\Delta H_{\mathrm{sv}}^{\circ}$, however, the values of the individual ions cannot be calculated except by the introduction of an extrathermodynamic assumption. Again, several such assumptions have been proposed. Of these, the assumption that $\Delta H_{\mathrm{tr}}\left(\mathrm{Ph}_{4} \mathrm{As}^{+}\right)=$ $\Delta H_{\mathrm{tr}}\left(\mathrm{Ph}_{4} \mathrm{~B}^{-}\right)$has become most widely used, as being both very reasonable and also easy to apply. ${ }^{36}$ Based on that assumption Krishnan and Friedman ${ }^{37}$ determined values of $\Delta H_{\text {tr }}^{\circ}$ of single ions for the transfer between the three solvents propylene carbonate, DMSO, and water. For the halide ions $\mathrm{Cl}^{-}, \mathrm{Br}^{-}$, and $\mathrm{I}^{-}, \Delta H_{\mathrm{tr}}^{\circ}(\mathrm{W} \rightarrow \mathrm{DMSO})$ were found to be $18.8,3.5$, and $-12.8 \mathrm{~kJ} \mathrm{~mol}^{-1}$, respectively, with errors not exceeding 1 or, at most, $2 \mathrm{~kJ}$ (cf. 
also Ref. 38, p. 19. These values together with the $\Delta H_{\mathrm{aq}}^{\circ}\left(\mathrm{L}^{-}\right)$-values given by Morris ${ }^{32}$ yield the absolute heats of solvation of the halide ions in DMSO, see note $b$ of Table 4. From these, the values of the heats of solvation of $\mathrm{Zn}^{2+}, \mathrm{Cd}^{2+}$, and $\mathrm{Hg}^{2+}$ in DMSO, can be calculated, Table 4 . The results show that also in DMSO, the values of $\Delta H_{\mathrm{sv}}^{\circ}\left(\mathrm{M}^{2+}\right)$ obtained from the chloride, bromide, and iodide data agree very well for each metal ion.

\section{DISCUSSION}

For the metal ions studied the heat of solvation is more exothermic in DMSO than in water, indicating a preference for DMSO. For $\mathrm{Zn}^{2+}, \mathrm{Cd}^{2+}$, and $\mathrm{Hg}^{2+}, \Delta H_{\mathrm{tr}}^{\circ}(\mathrm{W} \rightarrow \mathrm{DMSO})$ is found to be -60 , -67 , and $-76 \mathrm{~kJ} \mathrm{~mol}^{-1}$, respectively, Table 4 . Thus, the softer the metal ion, the stronger its preference for DMSO. In both water and DMSO the heat of solvation decreases considerably from $\mathrm{Zn}^{2+}$ to $\mathrm{Cd}^{2+}$ but increases a little from $\mathrm{Cd}^{2+}$ to $\mathrm{Hg}^{2+}$. The total heat is composed of contributions from electrostatic as well as covalent interactions between the metal ion and the solvent molecules. The electrostatic interaction decreases with increasing radius of the ion, i.e. in the order $\mathrm{Zn}^{2+}>\mathrm{Cd}^{2+}>\mathrm{Hg}^{2+}$ (for recent values of the octahedral ionic radii, see Refs. 4 and 39). The covalent interaction, on the other hand, increases as the metal ion becomes softer, i.e. in the order $\mathrm{Zn}^{2+}<\mathrm{Cd}^{2+}<\mathrm{Hg}^{2+}$. Evidently the sum of the two contributions might pass through a minimum, as is in fact observed for $\mathrm{Cd}^{2+}$.

The heats of solvation of the neutral complexes, $\mathrm{ML}_{2}$, should follow the same trend as those of the metal ions, if no special effects intervene. For all halides studied, $-\Delta H_{\mathrm{sv}}^{\circ}\left(\mathrm{ML}_{2}\right)$ is considerably higher in DMSO than in water, Table 1. This is, as previously noted, also the case for the free metal ions. For the complexes, however, the heat differences between the two solvents are relatively much larger than for the free ions. This is evident from the ratio $\Delta H_{\mathrm{tr}}^{\circ}(\mathrm{W} \rightarrow \mathrm{DMSO}) / \Delta H_{\mathrm{aq}}^{\circ}$ which for the free metal ions is $\approx 0.04$, much lower than for any of the complexes. For the complexes $\mathrm{HgL}_{2}$, the ratio even reaches values as high as $\approx 0.5$. The solvents thus interact much more specifically with the complexes $\mathrm{ML}_{2}$ than with the free metal ions. In fact, the absolute values of $-\Delta H_{\mathrm{tr}}^{\circ}(\mathrm{W} \rightarrow \mathrm{DMSO})$ for the complexes, 30 to $50 \mathrm{~kJ} \mathrm{~mol}^{-1}$ are not much smaller than for the free ions, 60 to $76 \mathrm{~kJ} \mathrm{~mol}^{-1}$; Table 1.
For both water and DMSO the values of $-\Delta H_{\mathrm{sv}}^{\circ}\left(\mathrm{ML}_{2}\right)$ are much higher for the zinc and cadmium halides than for the mercury halides. The reason is certainly that solvent molecules enter into a much closer contact with the metal ion in the case of $\mathrm{ZnL}_{2}$ and $\mathrm{CdL}_{2}$ than in the case of $\mathrm{HgL}_{2}$. The second zinc and cadmium complexes are in solution either octahedral or tetrahedral, ${ }^{11,12,38}$ with solvent molecules coordinated about as closely as the other ligands. In the nearly linear mercury complexes, on the other hand, the solvent to metal bonds are certainly all long ${ }^{8,9}$ and the interaction consequently much weaker.

Another very striking fact is that while for $\mathrm{HgL}_{2}$ and $\mathrm{CdL}_{2}$ the values of $-\Delta H_{\mathrm{sv}}^{\circ}\left(\mathrm{ML}_{2}\right)$ in both water and DMSO distinctly decrease in the order $\mathrm{Cl}^{-}>$ $\mathrm{Br}^{-}>\mathrm{I}^{-}$, the values for $\mathrm{Zn}^{2+}$ increase slowly in the same order. This is probably due to a combination of the following two effects.

Firstly, in the complexes $\mathrm{ZnL}_{2}$, where the forces between $\mathrm{L}^{-}$and the hard acceptor $\mathrm{Zn}^{2+}$ are of a mainly electrostatic character, the effective charge on the metal ion will be higher the lower the charge density on the ligand, and the higher the effective charge, the stronger the solvation. As the charge density decreases in the sequence $\mathrm{Cl}^{-}>\mathrm{Br}^{-}>\mathrm{I}^{-}$, the effective charge will increase and the solvation consequently become stronger in the same sequence. On the other hand, in complexes like $\mathrm{CdL}_{2}$ and $\mathrm{HgL}_{2}$ where the metal ions are soft, the interactions between the ligands and the central ions are of a rather covalent character. The effective charge on the metal ion will in such cases be lower the more covalent the bonding, i.e. the softer the ligand. As the softness increases in the sequence $\mathrm{Cl}^{-}<\mathrm{Br}^{-}<\mathrm{I}^{-}$, the effective charge for these soft metal ions decreases, and the solvation consequently becomes weaker in the same sequence.

Secondly, in the zinc chloride and bromide systems, the switch from octahedral to tetrahedral coordination in DMSO occurs mainly at the first step and is certainly complete at the second, while the process occurs later in the zinc iodide and in all the cadmium halide systems. Consequently, the heats of solvation of $\mathrm{ZnCl}_{2}$ and $\mathrm{ZnBr}_{2}$, forming exclusively tetrahedral complexes, should be expected to be relatively low compared to the other complexes which are more extensively solvated. For $\mathrm{ZnCl}_{2}$, the value of $-\Delta H_{\mathrm{sv}}^{\circ}$ is in fact even somewhat lower than that of $\mathrm{CdCl}_{2}$, though the opposite could be expected considering the values of $\Delta H_{\mathrm{sv}}^{\circ}$ of the respective metal ions. 
The two effects discussed are most likely interwoven. The high effective charge left on zinc iodide complexes permits the coordination of more solvent molecules at a later stage of the complex formation than in the case of the chloride and bromide systems, where the effective charge is lower.

Acknowledgement. We gratefully acknowledge the support given to this investigation by Statens naturvetenskapliga forskningsråd (The Swedish Natural Science Research Council).

\section{REFERENCES}

1. Bol, W., Gerrits, G. J. A. and van Panthaleon van Eck, C. L. J. Appl. Crystallogr. 3 (1970) 486.

2. Johansson, G. Acta Chem. Scand. 25 (1971) 2787.

3. Ohtaki, H., Maeda, M. and Ito, S. Bull. Chem. Soc. Jpn. 47 (1974) 2217.

4. Sandström, M., Persson, I. and Ahrland, S. To be published.

5. Sandström, M. Acta Chem. Scand. A 31 (1977) 141.

6. Sandström, M. and Johansson, G. Acta Chem. Scand. A 31 (1977) 132.

7. Johansson, G., Pocev, S. and Triolo, R. Personal communication.

8. Gaizer, F. and Johansson, G. Acta Chem. Scand. 22 (1968) 3013.

9. Sandström, M. To be published.

10. Wells, A. F. Structural Inorganic Chemistry, 4th Ed., Clarendon Press, Oxford 1975.

11. Ahrland, S. and Björk, N. O. Acta Chem. Scand. A 30 (1976) 257.

12. Ahrland, S., Björk, N. O. and Portanova, R. Acta Chem. Scand. A 30 (1976) 270.

13. Gerding, P. Acta Chem. Scand. 23 (1969) 1695.

14. Ahrland, S. and Kullberg, L. Acta Chem. Scand. 25 (1971) 3457.

15. Ahrland, S. and Björk, N. O. Acta Chem. Scand. A 28 (1974) 823.

16. Kullberg, L. Acta Chem. Scand. A 28 (1974) 979.

17. Christensen, J. J., Izatt, R. M., Hansen, L. D. and Hale, J. D. Inorg. Chem. 3 (1964) 130.

18. Tyrrel, H. J. V. and Richards, J. J. Chem. Soc. (1953) 3812; see Gmelin $\mathrm{Hg} \mathrm{B2,} \mathrm{p.} 766$.

19. Gallagher, P. K. and King, E. L. J. Am. Chem. Soc. 82 (1960) 3510.

20. Rice, D. W. and Gregory, N. W. J. Phys. Chem. 72 (1968) 3361.

21. Brewer, L., Somayajulu, G. R. and Brackett, E. Chem. Rev. 63 (1963) 111.

22. Cubicciotti, D., Eding, H. and Johnson, J. W. J. Phys. Chem. 70 (1966) 2989.

23. Gerding, P. and Jönsson, I. Acta Chem. Scand. 22 (1968) 2247.
24. Gerding, P. Acta Chem. Scand. 20 (1966) 79.

25. Bernhard, M. A., Busnot, F. and Le Querler, J. F. Bull. Soc. Chim. Fr. (1972) 4523.

26. Ahrland, S., Persson, I. and Portanova, R. To be published.

27. Lewis, G. N. and Randall, M. Thermodynamics (revised by Pitzer, K. S. and Brewer, L.) Appendix 7, McGraw-Hill, New York 1961.

28. Sharpe, A. G. In Gutmann, V., Ed., Halogen Chemistry, Academic, London and New York 1967, Vol. 1.

29. Berry, R. S. and Reimann, C. W. J. Chem. Phys. 38 (1963) 1540.

30. Handbook of Chemistry and Physics, 55th Ed., CRC, Cleveland, Ohio 1974.

31. Halliwell, H. F. and Nyburg, S. C. Trans. Faraday Soc. 59 (1963) 1126.

32. Morris, D. F. C. Struct. Bonding (Berlin) 4 (1968) 63.

33. Noyes, R. M. J. Am. Chem. Soc. 84 (1962) 513.

34. Ladd, M. F. C. and Lee, W. H. J. Inorg. Nucl. Chem. 13 (1960) 218.

35. Christensen, J. J., Izatt, R. M. and Eatough, D. Inorg. Chem. 4 (1965) 1278.

36. Cox, B. G. and Parker, A. J. J. Am. Chem. Soc. 95 (1973) 402.

37. Krishnan, C. V. and Friedman, H. L. J. Phys. Chem. 73 (1969) 3934.

38. Ahrland, S. In Lagowski, J. J., Ed., The Chemistry of Non-Aqueous Solvents, Academic, New York and London 1978, Vol. V, p. 1.

39. Shannon, R. D. and Prewitt, C. T. Acta Crystallogr. B 25 (1969) 925.

Received November 22, 1977. 